\title{
APPLICATION OF INSPECT SYSTEM FOR THE ANALYSIS OF TIDE, WAVE, TSUNAMI AND STORM SURGE ON THE COASTS OF SHIKOKU ISLAND, JAPAN
}

\author{
Hidenori Shibaki ${ }^{1}$, Nobuhiko Hara ${ }^{2}$ and Masaki Mimura ${ }^{3}$
}

\begin{abstract}
The INSPECT (Integrated Numerical research System for Prevention and Estimation of Coastal disasTer) system was developed for numerical analysis of oceanographical disaster phenomena in coastal and estuarine areas. The INSPECT consists of three numerical simulation models (Wave, Storm Surge and Tsunami models), their supporting sub-systems and supporting databases. With this system, various coastal protection works can be more reliable designed. The paper presents an outline of the design, basic theory of numerical research and applications of the system. The analysis of tide, Wave, Tsunami and storm surge on the coasts of Shikoku Island in Japan is performed by using INSPECT.
\end{abstract}

Keywords: tide; wave hindcast; tsunami; storm surge; disaster prevention; INSPECT system

\section{INTRODUCTION}

Severe environmental conditions persist along the coast of Japan with huge waves, storm surges and tsunamis. Oceanographical disasters are occurring every year around the coastal and estuarine areas of Japan. In September 1959, an abnormal high storm surge caused a coastal disaster with flooding over a large area around the Ise Bay, which is located in the center of Japan, and with the loss of more than 5,000 lives. This storm surge was generated by the Typhoon number 5915 (named Isewan Typhoon), and it is the largest one in the historical records of Japan. In May 1960, the Chilian earthquake tsunami caused a coastal disaster with an inundation of large coastal areas facing the Pacific Ocean. It was a typical trans-oceanic tsunami that propagated across the Pacific Ocean. Against these coastal disasters, the research on prevention of coastal disaster is actively conducted, and many coastal structures have been planned and built for disaster mitigation. Hard countermeasures, like the construction of various structures as coastal dikes, seawalls and breakwaters, are effective to reduce the damage up to the level of disasters to which the structures were designed. However, the hard countermeasures have a limitation in their disaster prevention capacity against disasters over the design level. To remedy the deficiency of hard ones, soft countermeasures, which mean a provision of the information on the disaster mitigation and evacuation methods, are promoted. The soft countermeasures can be more useful for disaster mitigation than the hard ones, depending on the situation.

To determine design conditions and to prepare disaster-related information, the characteristics of oceanographical disaster phenomena must be clarified with scientific methods. Numerical simulation is a powerful tool for the analysis of disaster phenomena that have large temporal and spatial scales. The INSPECT (Integrated Numerical research System for Prevention and Estimation of Coastal disasTer) system has been developed for coastal protection works composed of hard and soft countermeasures.

The simulations of tide, wave, tsunami and storm surge are performed on the coast of the Shikoku Island, Japan. The Shikoku Island is faced to the Seto Inland Sea and Tosa Bay. The Seto Inland Sea is composed several water ways, basins and straits, and Tosa Bay is located in north-western boundary of the Pacific Ocean. The coasts of the Shikoku Island are characterized by local hydraulic phenomenon on the coast, respectively. The information of simulation are analyzed to clarify the characteristics of tide, wave, tsunami and storm surge around the coasts of the Shikoku Island.

Several view points of analysis are following:

1. Distribution of amplitude and phase of astronomy tide and tidal current generated by tide forth

2. Distribution of wave height in the open sea, coast and near shore area generated by typhoon storm

3. Distribution of maximum height and natural frequency generated by tsunami propagation

4. Distribution of tide anomaly composed with free and driving forth wave generated by storm surge

The paper presents an outline of the system and the analysis of tide, Wave, Tsunami and storm surge on the coasts of Shikoku Island in Japan.

\footnotetext{
${ }^{1}$ Disaster Prevention and Hydraulic Engineering, ECOH Corp., 2-6-4 Kita-Ueno, Taito-Ku, Tokyo 110-0014, Japan

${ }^{2}$ Disaster Prevention and Hydraulic Engineering, ECOH Corp., 2-6-4 Kita-Ueno, Taito-Ku, Tokyo 110-0014, Japan

${ }^{3}$ Takamatsu Res. \& Eng. Office for Port and Airport, Shikoku Regional Development Bureau, Ministry of Land Infrastructure and Transport, 1-6-1, Ban-Cho, Takamatsu 760-0017, Japan
} 


\section{OUTLINE OF INSPECT SYSTEM}

Composition and Functions of the INSPECT System

The INSPECT system consists of three numerical simulation models (Wave, Storm Surge and Tsunami models), their supporting sub-systems and supporting databases. Fig. 1 shows the composition and functions of the system. The flow chart for the analysis of the design tide level, using the INSPECT system, is presented in Fig. 2. Several systems, supporting sub-systems and databases are utilized for such analyses.

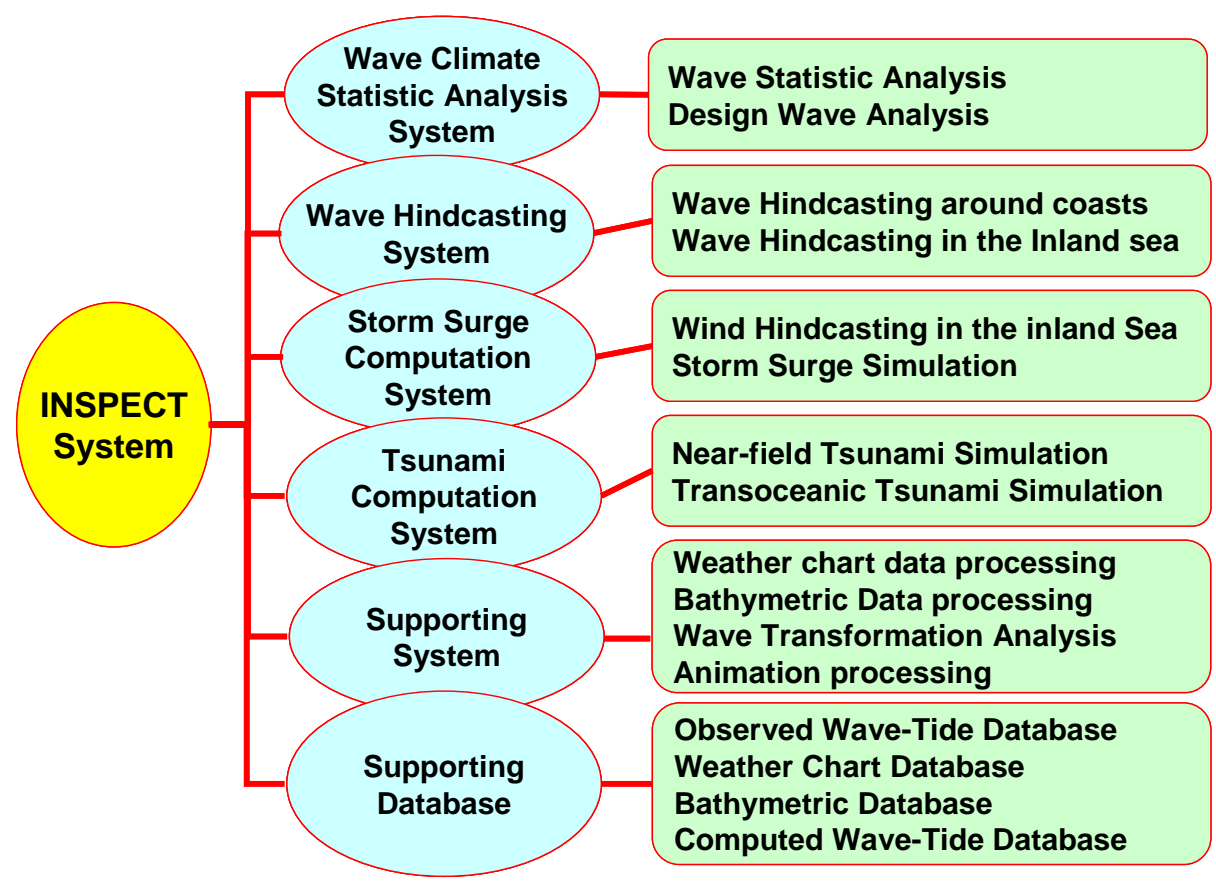

Figure 1. Composition and functions of the INSPECT.

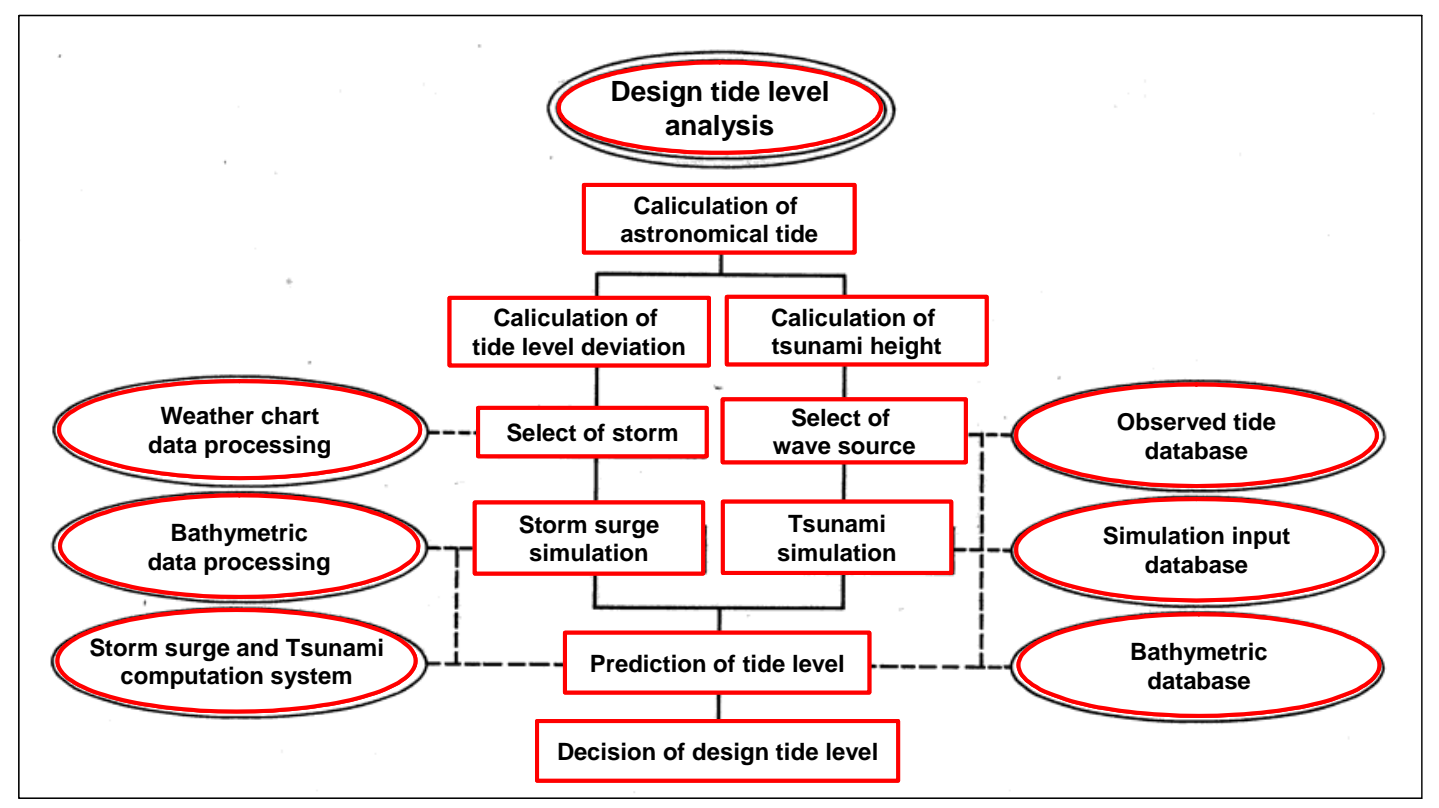

Figure 2. Flow chart for the analysis of the design tide level using the INSPECT system. 
Numerical Simulation Models in INSPECT System

The wave and storm surge model has been developed for numerical studies on several coastal areas, as severe storm surges are generated by large typhoons. The accuracy of wave and storm surge simulation has been verified with the data of observed waves and tide anomaly. The tsunami model was initially developed to simulate propagation and splitting of solitary wave, which was generated by the Nihonkai-Chubu earthquake tsunami in 1983. The accuracy of tsunami simulation has been verified with the data of several laboratory experiments.

The INSPECT wave model is a shallow-water wave hindcasting model, based on spectral calculations, incorporating wave generation, wave decay and wave transformation. The model is able to simulate wave fields composed of wind waves and swells. The governing equation of wave hindcasting is the energy balance equation.

The left diagram in Fig. 3 shows the spatial variation of maximum significant wave height generated by Typhoon 7010 around the coast of the Tosa Bay. The significant wave height grows more than $10 \mathrm{~m}$ in the offshore area, and wave transformation is computed in a shallow-water area. In the right diagram, the spatial variation of wave height close to coastal line is presented. The processes of wave refraction, wave diffraction and wave shoaling outside the surf zone, and wave decay by wave breaking inside the surf zone are taken into account in this wave model.
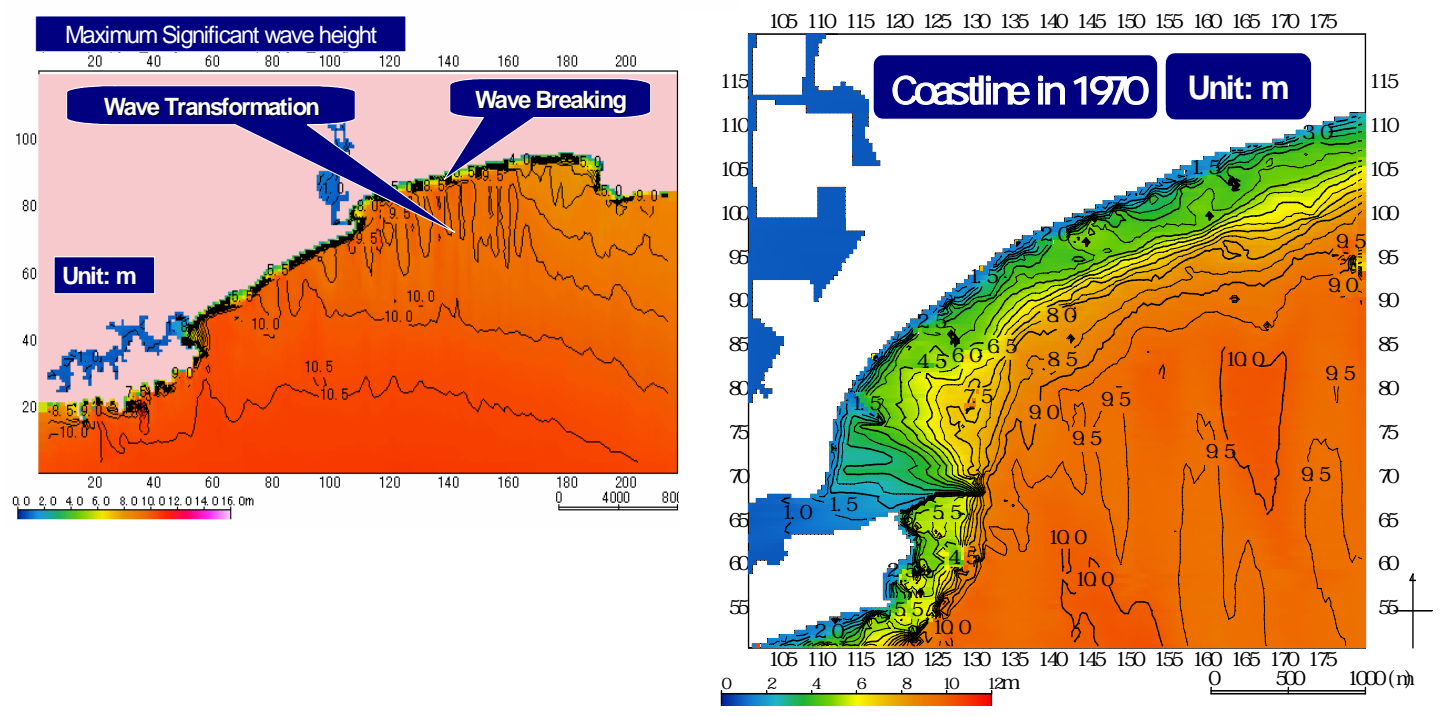

Figure 3. Spatial variation of maximum significant wave height upon the attack of Typhoon 7010 around the coast of the Tosa Bay (left diagram) and around the coastlines of Kochi Port (right diagram).

The INSPECT storm surge model gives an accurate tide anomaly by incorporating several effects such as multi-level flows, density stratification, wave setup, river discharge and inundation. The magnitude of wave setup can be calculated from the divergence of the radiation stresses. The results of wave hindcasting with a shallow-water wave model are used for the calculation of the radiation stresses. The radiation stresses for each layer utilize the formulas by Longuet-Higgins and Stewart (1964). The basic equations of storm surge model are the multi-level continuity and momentum equations integrated for each layer. In the momentum equations, the shear stresses (wind stress at the sea surface, inner stress between two layers and bottom shear stress), the pressure gradients (atmospheric pressure, water level and water density) and the divergence of the radiation stresses are taken into consideration. More details about basic equations of simulation model are explained in Shibaki and Watanabe (2002).

The left diagram in Fig. 4 shows the spatial variation of the maximum deviation of tide level generated by Typhoon 7010 around the coast of the Tosa Bay. The increase of tide level deviation is remarkable near the coastline owing to the effect of wave setup. The increase of tide level deviation along the coastline contributes to the increase of tide level in the inner bay areas. Wave setup is generated by wave actions inside the surf zone. The right diagram shows the divergence vector field of radiation stresses of waves. The distribution of maximum tide anomaly by storm surge of typhoon 
7010 in the Kochi Port is shown in Fig. 5. The increase of tide anomalies have occurred near the coastline by the effect of wave setup. And, the increase of tide anomaly in the inner bay area has occurred with contribution of the tide anomaly along the coast line of outer bay. Simultaneously, the decrease of tide anomaly in the inner bay area has occurred by the effect of inundation. The present storm surge simulation model incorporates the effects of inundation as explained before. Figure 5 shows that comparison of maximum tide level deviations in Kochi Port calculated with the effect of inundation and without inundation upon attack of a T7010-class typhoon. The left diagram shows the spatial variation of maximum tide level deviation with inundation and the right diagram is that without inundation. Comparison of the left and right diagrams of Figure 5 clarifies the change of tide level deviation due to the effect of inundation. The result without inundation is larger than that with inundation by about $0.3 \mathrm{~m}$ in an inner bay.

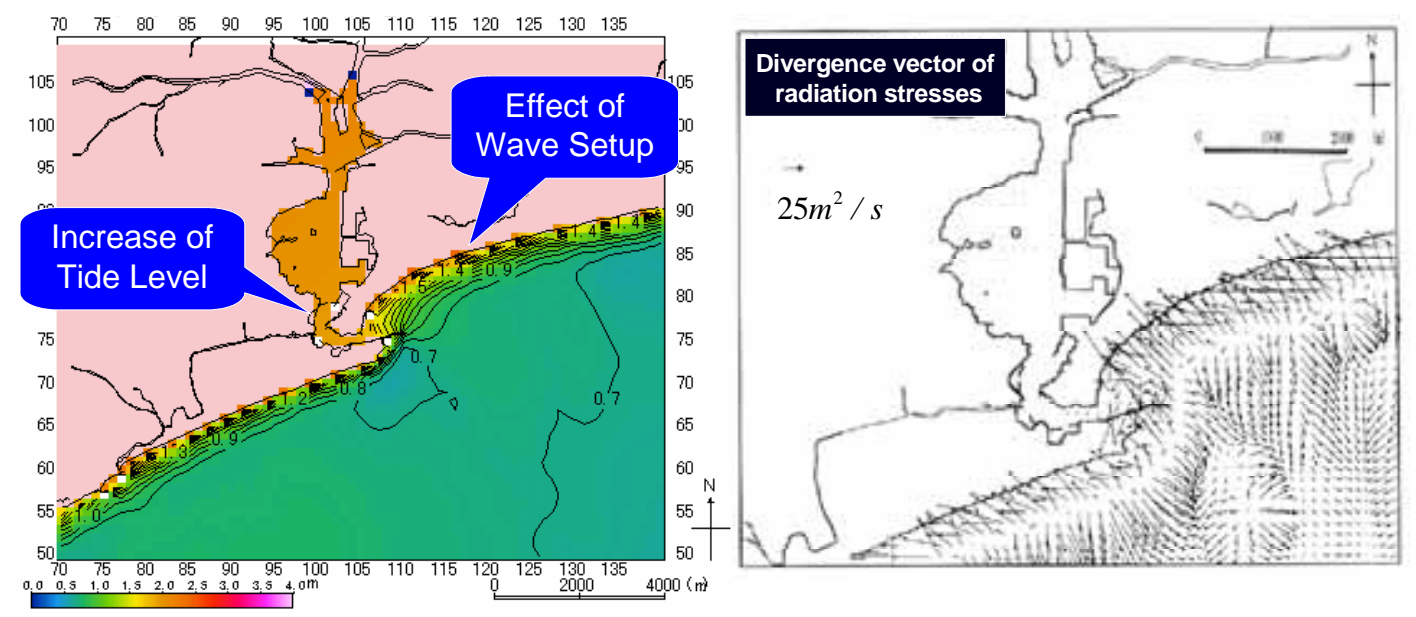

Figure 4. Spatial variation of the maximum deviation of tide level (left diagram) and divergence vector field of radiation stresses of waves (right diagram) around the coast of the Tosa Bay generated by Typhoon 7010.
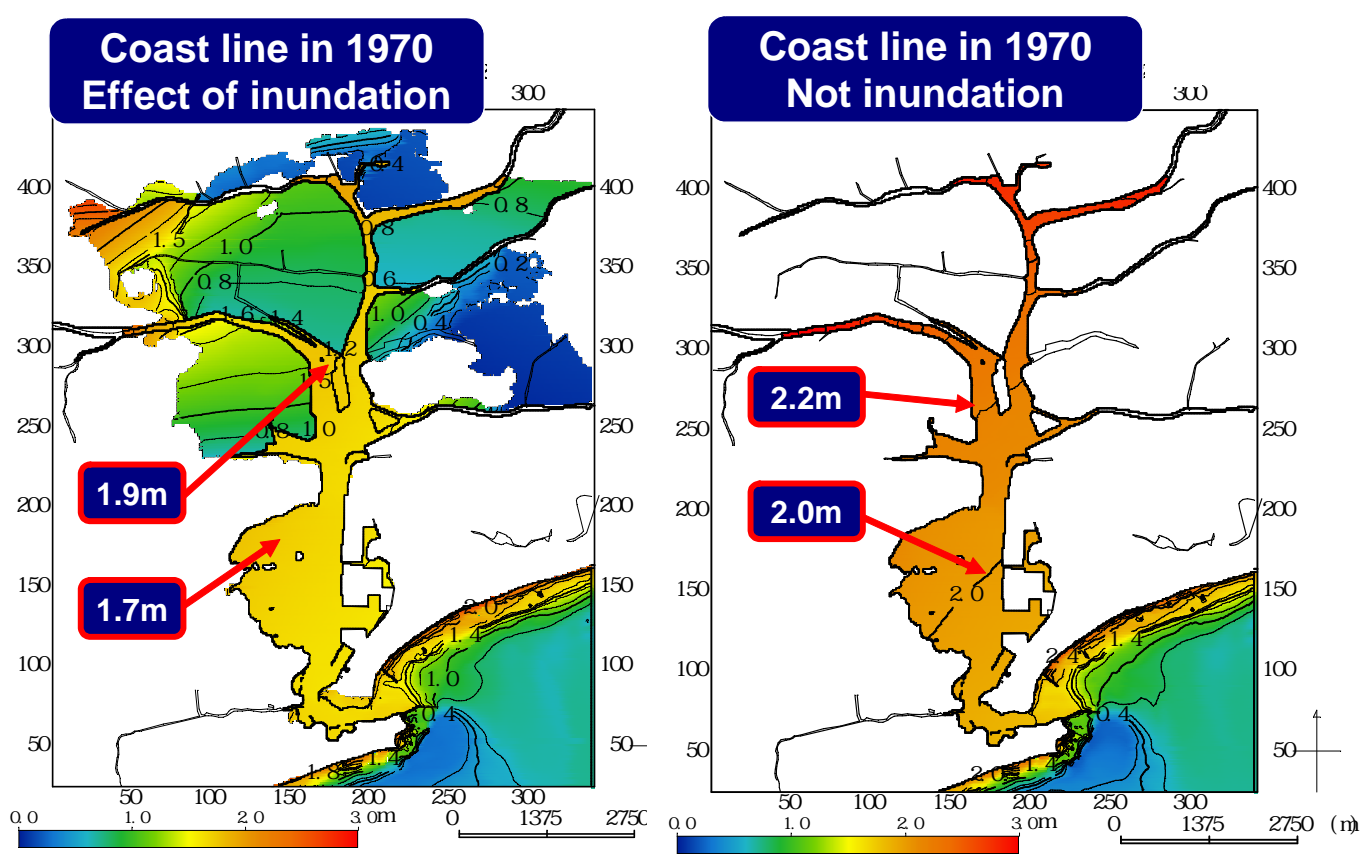

Figure 5. Comparison of maximum deviations of tide level in Kochi Port calculated with the effect of inundation (left diagram) and without inundation (right diagram) upon attack of a T7010-class typhoon. 
The third numerical simulation model in the INSPECT system is tsunami model. The basic equations of INSPECT tsunami model are selected from several types. The fault deformation model is used as initial condition. The bottom friction is estimated by manning roughness coefficient with land conditions. Covering ration of land structures is used to land condition. The INSPECT tsunami model gives an accurate estimate of wave height and velocity by incorporating several effects such as nonlinear wave dispersion, wave breaking and bottom friction estimated with land conditions. Fig. 6 shows the tsunami propagation computed by the nonlinear dispersive equation model proposed by Iwase and Imamura (2003). The process of generation of soliton fission waves at the depth of about 8 $\mathrm{m}$ by the leading wave of the 1983 Nihonkai-Chubu earthquake tsunami and the breaking of these waves at the depth from 6 to $4 \mathrm{~m}$ is presented in the upper diagram. The lower diagrams show the highest level and the inundation region of the tsunami on the land computed by the present model. This tsunami simulation has been applied with the Aida fault model (1984) as the initial condition and yielded the results more accurate and stable than the shallow water equation models.

The spatial distribution of the maximum tsunami height of the 1960 Chilian earthquake tsunami in the Pacific Ocean computed by the linear dispersive equation model is shown in Fig. 7. The main direction of the trans-oceanic propagation tsunami is computed toward northwest and the energy of tsunami is seen to propagate toward the Japan coasts. Incident waves of this tsunami are allowed to propagate through the open boundary of the region near the Japan coasts, and they are employed as the input data for the numerical simulation around the Japan coasts.
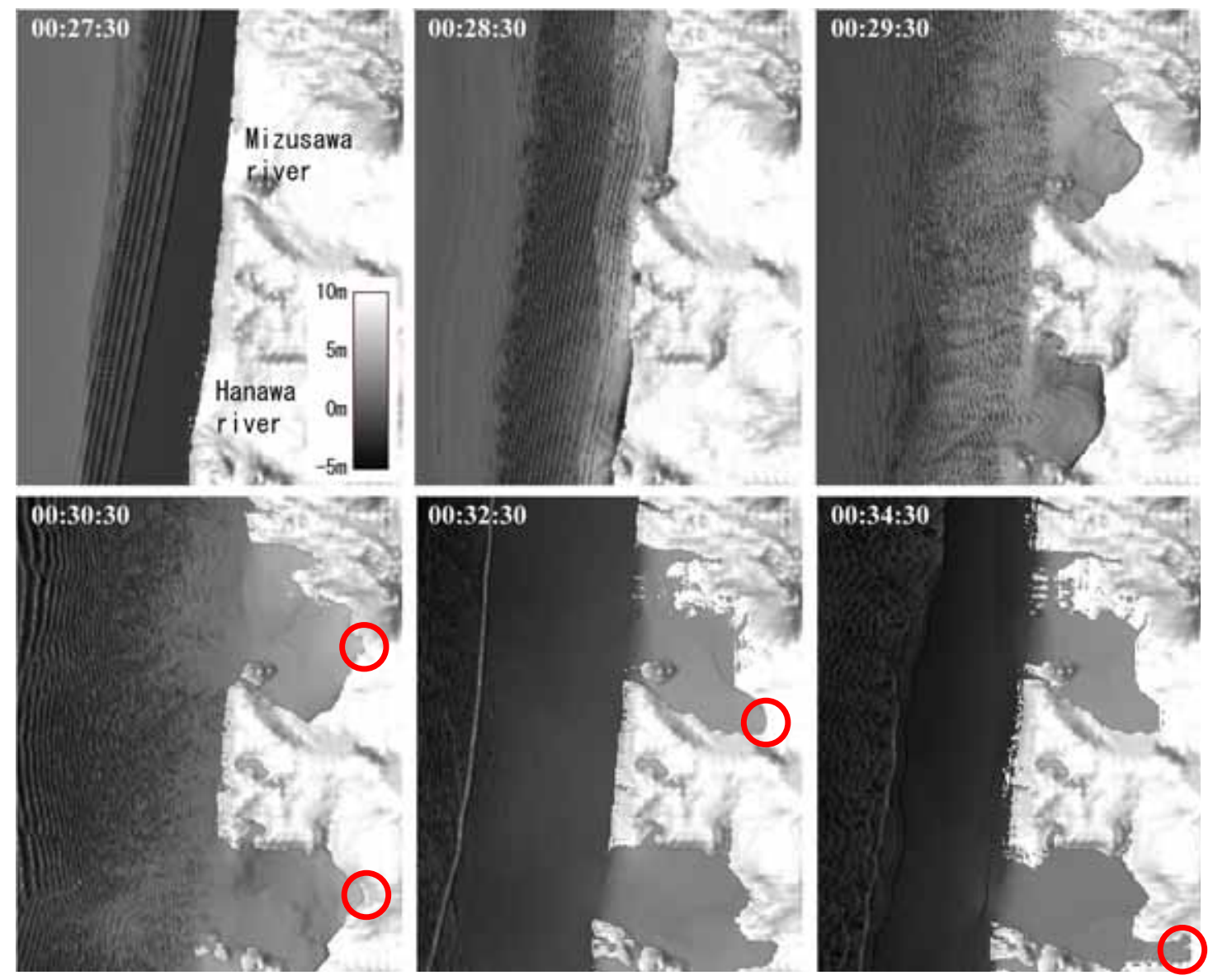

Figure 6. Tsunami propagation computed by the nonlinear dispersive equation model on the north Akita coast, circles are the highest level of the tsunami on the land. 


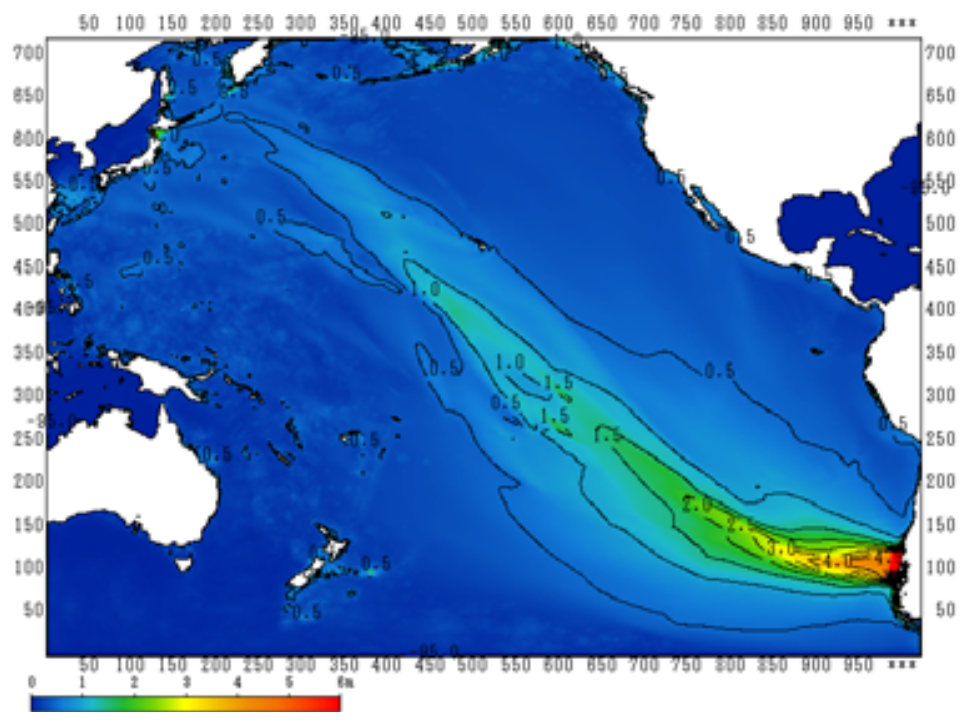

Figure 7. Distribution of the maximum tsunami height of the 1960 Chilian earthquake tsunami in the Pacific Ocean computed by the linear dispersive equation model.

\section{DATABASE AND APPLICATION IN INSPECT SYSTEM}

The INSPECT system includes several databases for numerical simulation on coastal disasters. Fig. 8 shows a three-dimensional view of the sea bottom topography around Japan and the land topography of Japan. The data around the target area are selected from a topographic database before the performance of numerical simulations in the specific area. Fig. 9 shows a three-dimensional view of the topography of and buildings in an area selected for numerical simulation of the inundation. This diagram is made by using GIS data about the information of buildings.

Fig. 10 shows a digital weather chart and wind vector field computed with weather chart. The hybrid wind hindcasting model in combination with a gradient wind model and a typhoon model is utilized for the calculation of wind fields. The circular pressure distribution is used in the typhoon model, and wind hindcasting using the typhoon model is applied to the circular pressure fields influenced by a typhoon.

Fig. 11 shows a two-dimensional tsunami hazard map with the information of tsunami inundation height, topography, buildings, and routes at urban area. The tsunami inundation heights were calculated by numerical simulation for the purpose of tsunami evacuation planning. Similar maps have been prepared at several tsunami hazard areas in Japan. Fig. 12 shows three-dimentional view of topography and buildings together with the simulated inundation field. Such an application of numerical tsunami simulation helps citizens to understand clearly the tsunami damage and provides the useful information about the hazardous areas.

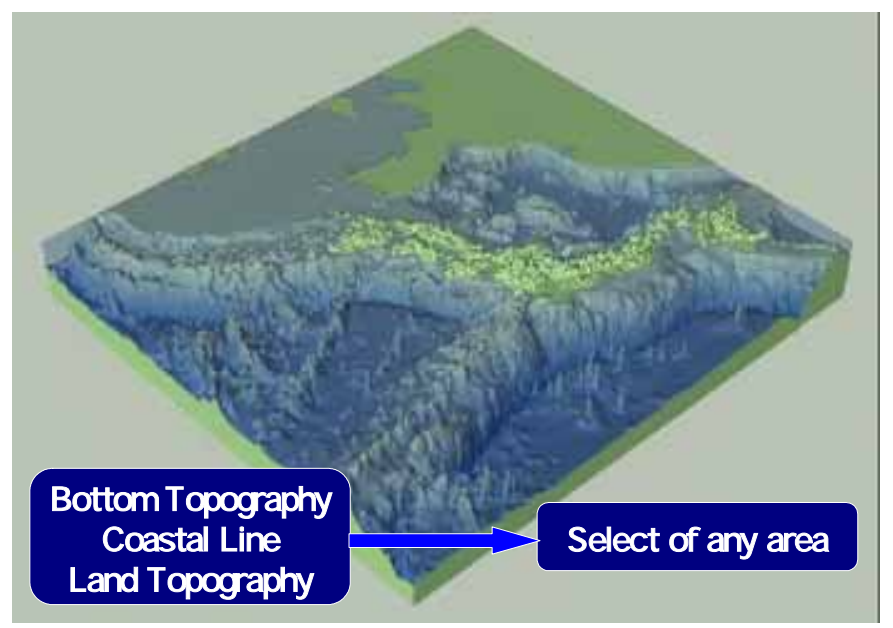

Figure 8. Three-dimensional view of sea bottom topography around Japan and land topography of Japan. 


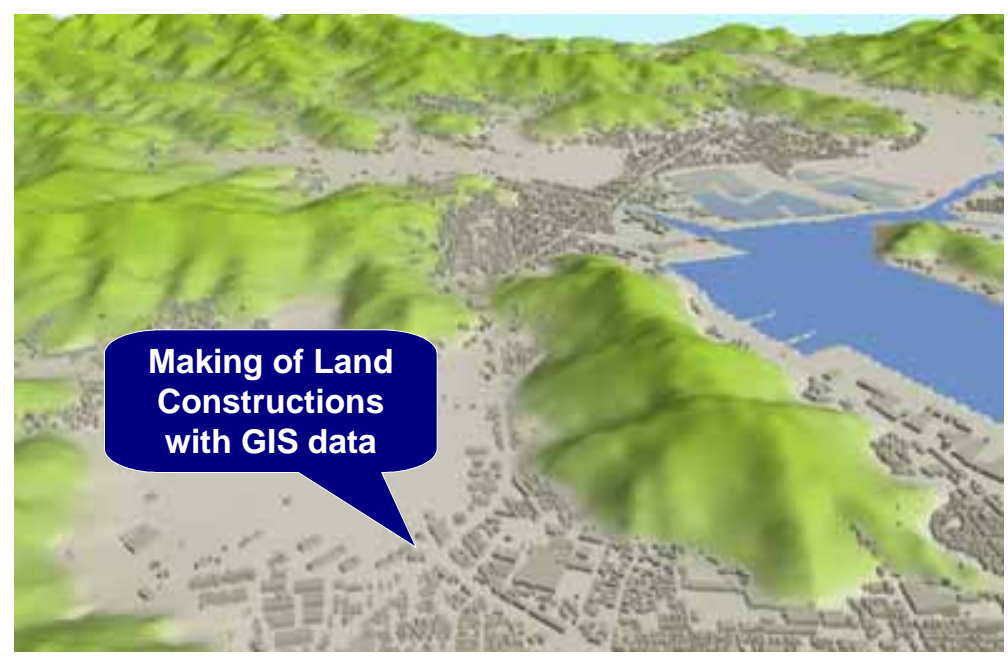

Figure 9. Three-dimensional view of topography and buildings.
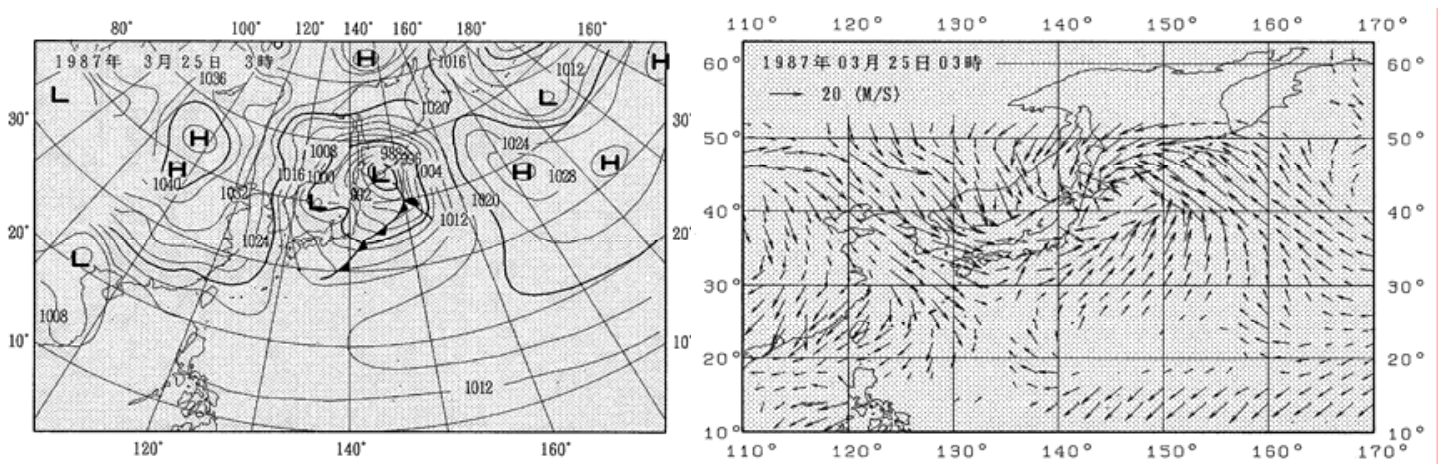

Figure 10. A digital weather chart and wind vector field computed with weather chart.

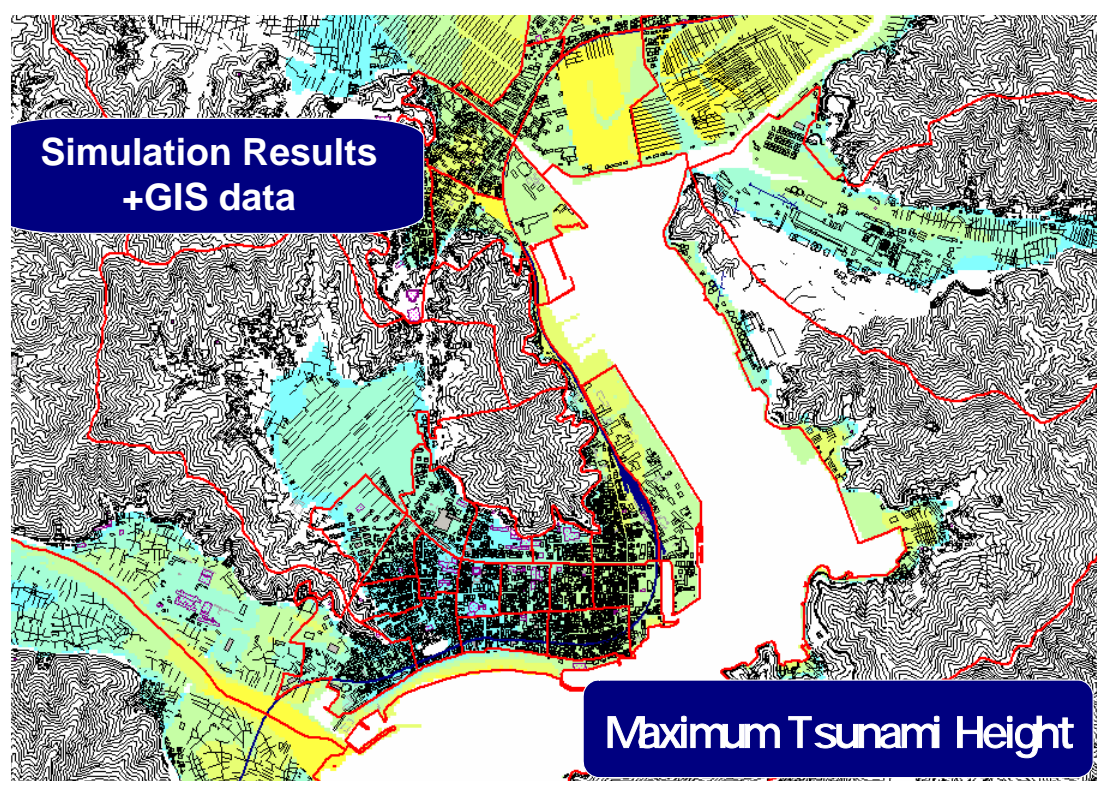

Figure 11. Two-dimensional tsunami hazard map informed with tsunami inundation height, topography, buildings, and routes at urban area. 


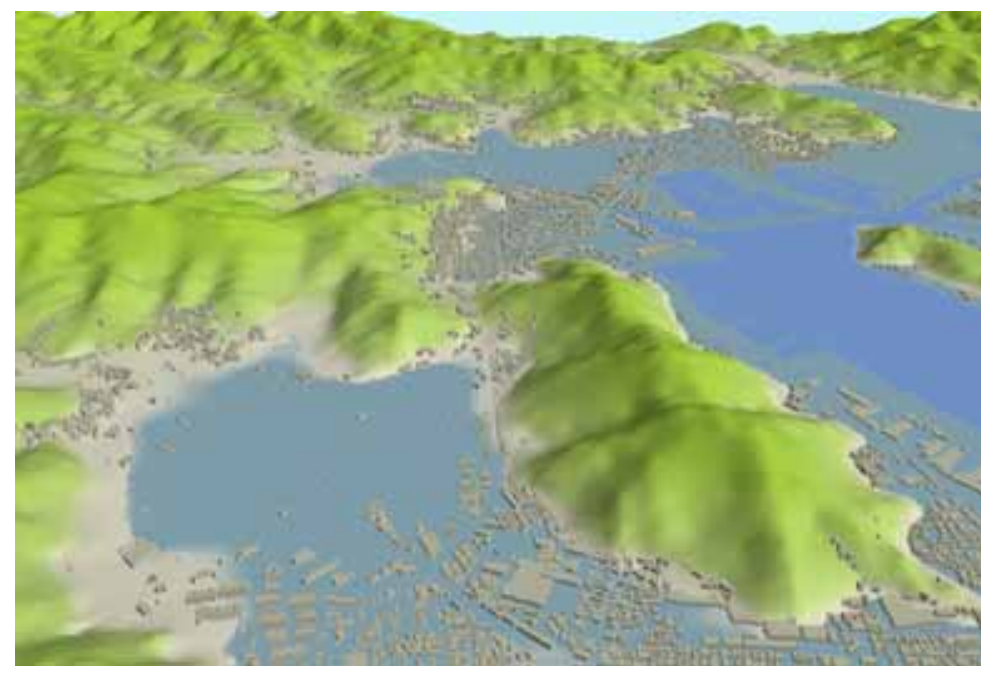

Figure 12. Three-dimensional view of topography and buildings together with simulated inundation field.

\section{ANALYSIS OF SIMULATION RESULT}

Outline of analysis using INSPECT system

The Shikoku Island is faced to the Seto Inland Sea and north-western boundary of the Pacific Ocean. The Seto Inland Sea is composed several water ways, basins and straits. The coasts are characterized by local hydraulic phenomenon on the coast, respectively. The information of simulation are analyzed to clarify the characteristics of tide, wave, tsunami and storm surge around the coasts. Several view points of analysis are following.

1. Distribution of amplitude and phase of astronomy tide and tidal current generated by tide forth.

2. Distribution of wave height in the open sea, coastal sea and near shore area generated by typhoon.

3. Distribution of maximum height and natural frequency generated by tsunami propagation.

4. Distribution of tide anomaly composed with free and driving forth wave generated by storm surge.

Fig. 13 shows the location of target area applied the INSPECT system. Right 3D-diagram shows the topography around Japan. Left diagram shows the location of Shikoku Island and Seto Inland Sea, which is applied area. The Shikoku Island is faced to the Seto Inland Sea and north western part of Pacific Ocean. Shikoku Island is about $250 \mathrm{~km}$, and the Seto Inland Sea is about $500 \mathrm{~km}$ from east to west. The Seto Inland Sea is composed several channels, straits and basins.

Fig. 14 shows the bottom topography of study area. The study area covers the south coast of Japan and the northwestern part of Pacific. This area covers the route of attacked typhoons to Japan, and covers the source of earthquake tsunami. Red circle in this diagram shows the location of Shikoku Island. Location of target points for numerical simulation is shown in this diagram. Tsunami simulation is carried out at the Suzaki Port. Wave and Storm Surge simulation carried out at the Kochi Port. Two ports located the south coast of Shikoku Island and faced to the Pacific Ocean.
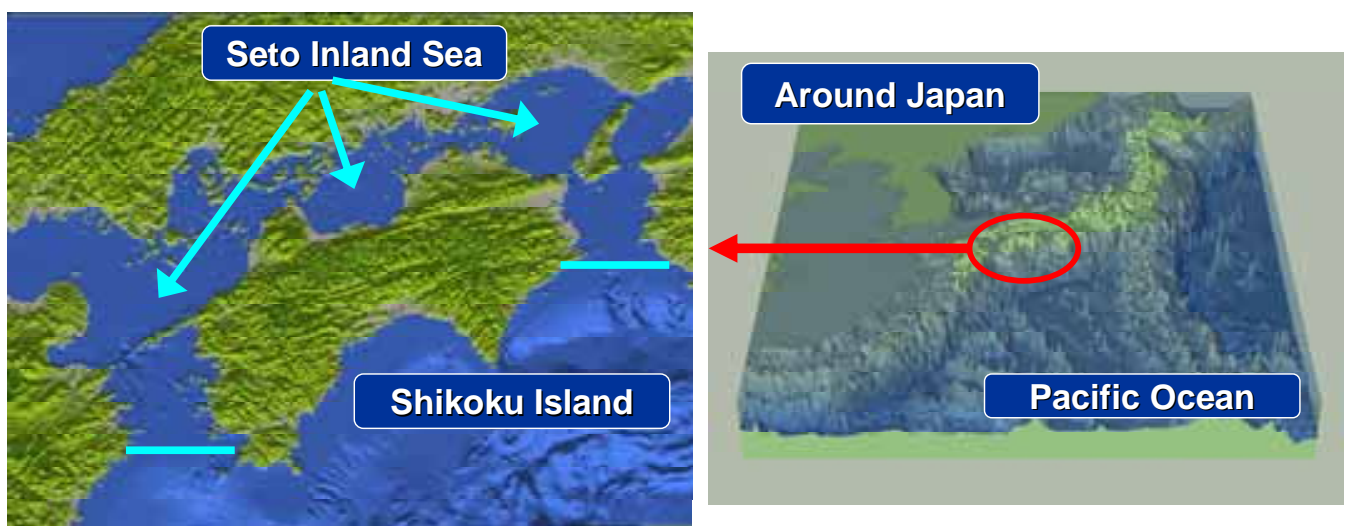

Figure 13. The location of target area applied the INSPECT system. Right 3D-diagram shows the topography around Japan. Left diagram shows the location of Shikoku Island and Seto Inland Sea. 


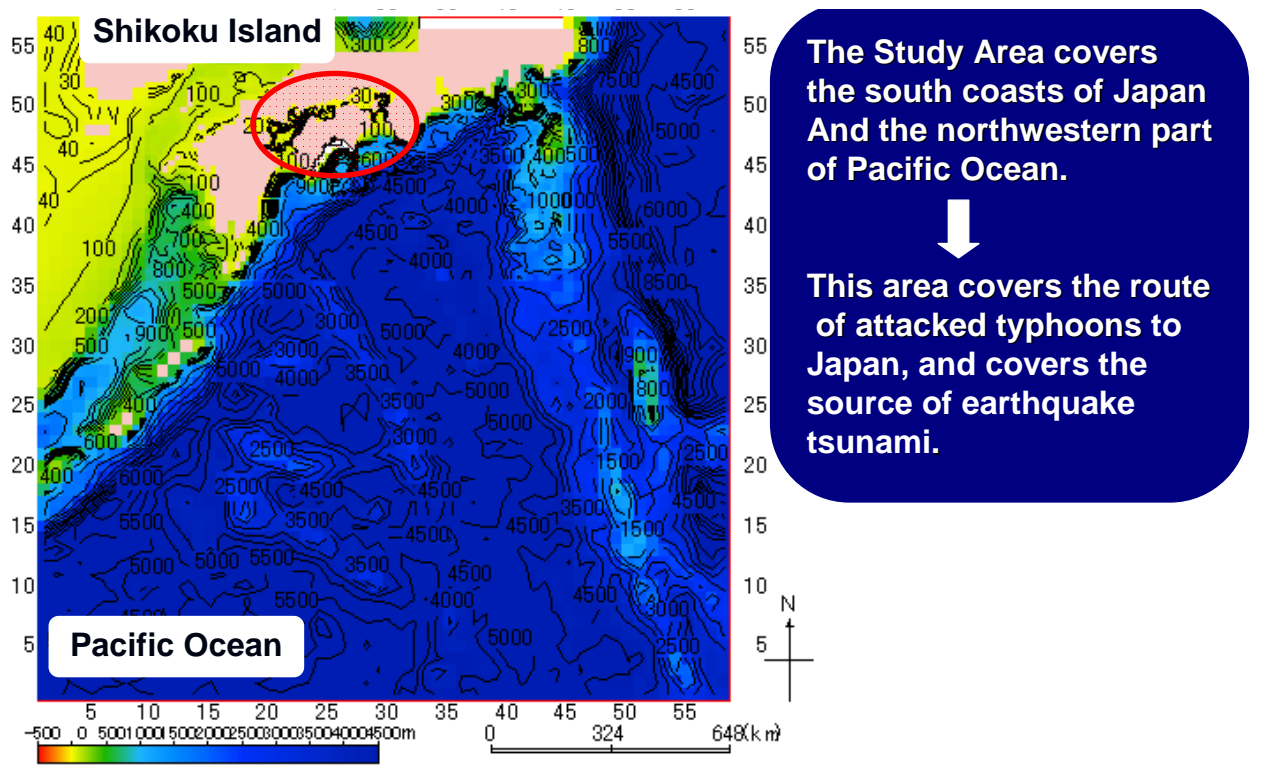

Figure 14. Bottom topography of study area applied to Simulation about Wave, Strom Surge and Tsunami on the Coasts of Shikoku Island.

Analysis of Tide and Tidal current

The tide and tidal current simulation model is a supporting one for coupling with tsunami and storm surge model. Tide and Tidal current model is similar with Storm Surge model. The Basic Equation is Nonlinear Shallow Water Equation. Multi-Level Continuity and Momentum Equations integrated for each layer. Tidal oscillation of typical tidal components is used for open boundary condition. The information of NAO.99Jb model is refered. This model is the global ocean tide simulation model.

Simulations in the INSPECT system are used nesting method. Fig. 15 shows the arrangement of grids for nesting method. Blue lines are locations of open boundaries. The fine grid size is able to select for the region of Seto Inland Sea. Fig. 16 shows the comparison between simulation and observation about tidal oscillation. Tidal oscillations are reproduced observed one by tidal simulation.

Fig. 17 shows the characteristic of tide and tidal current in the Seto Inland Sea. Tidal wave propagates in the open sea area, and propagate into Seto Inland Sea throw the two channels. The eastern one is Kii channel and the western one is Bungo Channel. The phase of tide is nearly equal to one of tidal current in Bungo and Kii Channels. The right diagram shows the relation between tide oscillation and tidal current oscillation. Black line shows tide oscillation and green line shows tidal current oscillation in this diagram. On the other hand, the phase of tide is different about 90 degrees from one of tidal current in the center basin of the Seto Inland Sea.

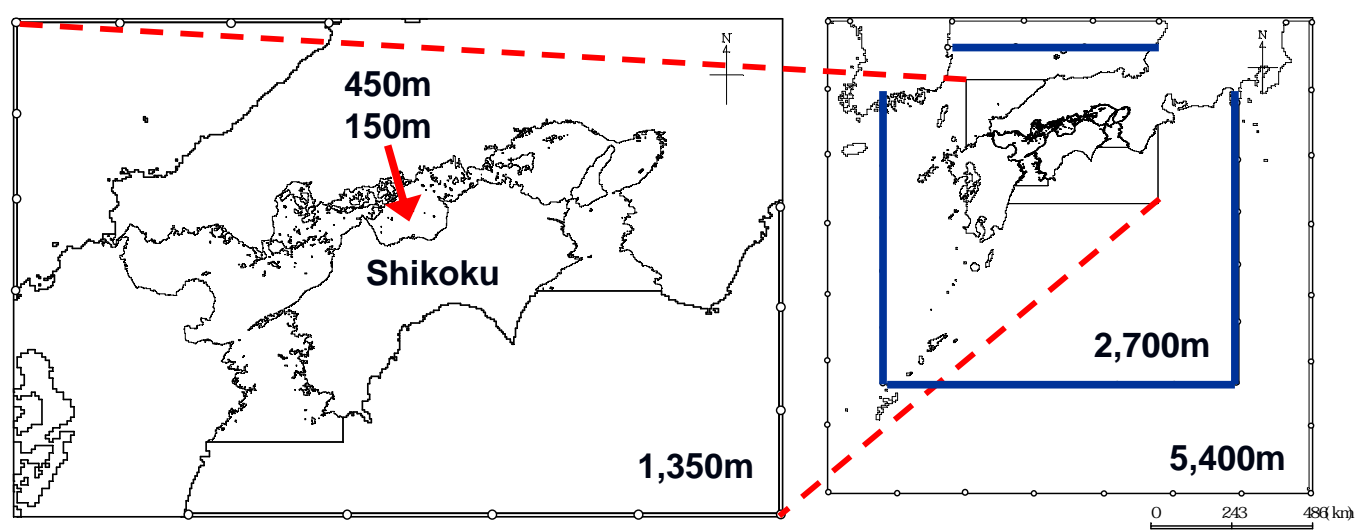

Figure 15. The arrangement of grid size for several regions by the nesting method. 


\section{Stn.34 Takamatsu}
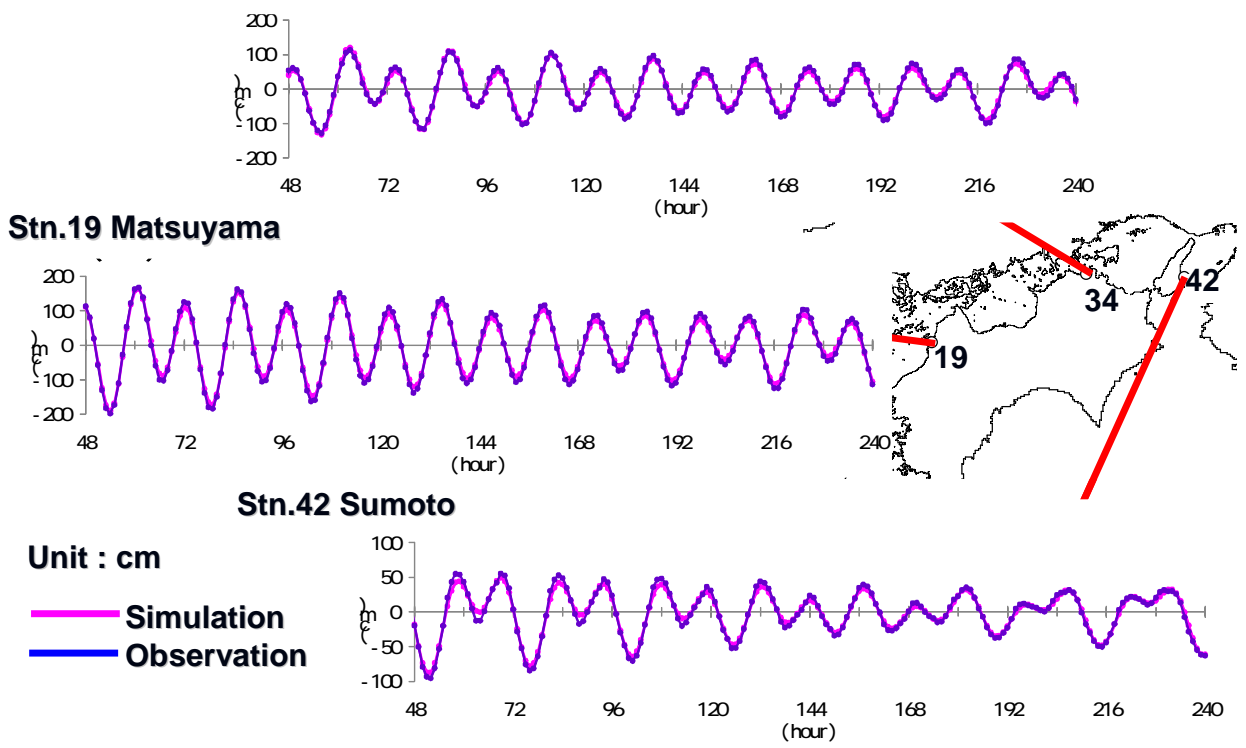

Figure 16. Comparisons between simulation and observation about tidal oscillation in Seto Inland Sea.
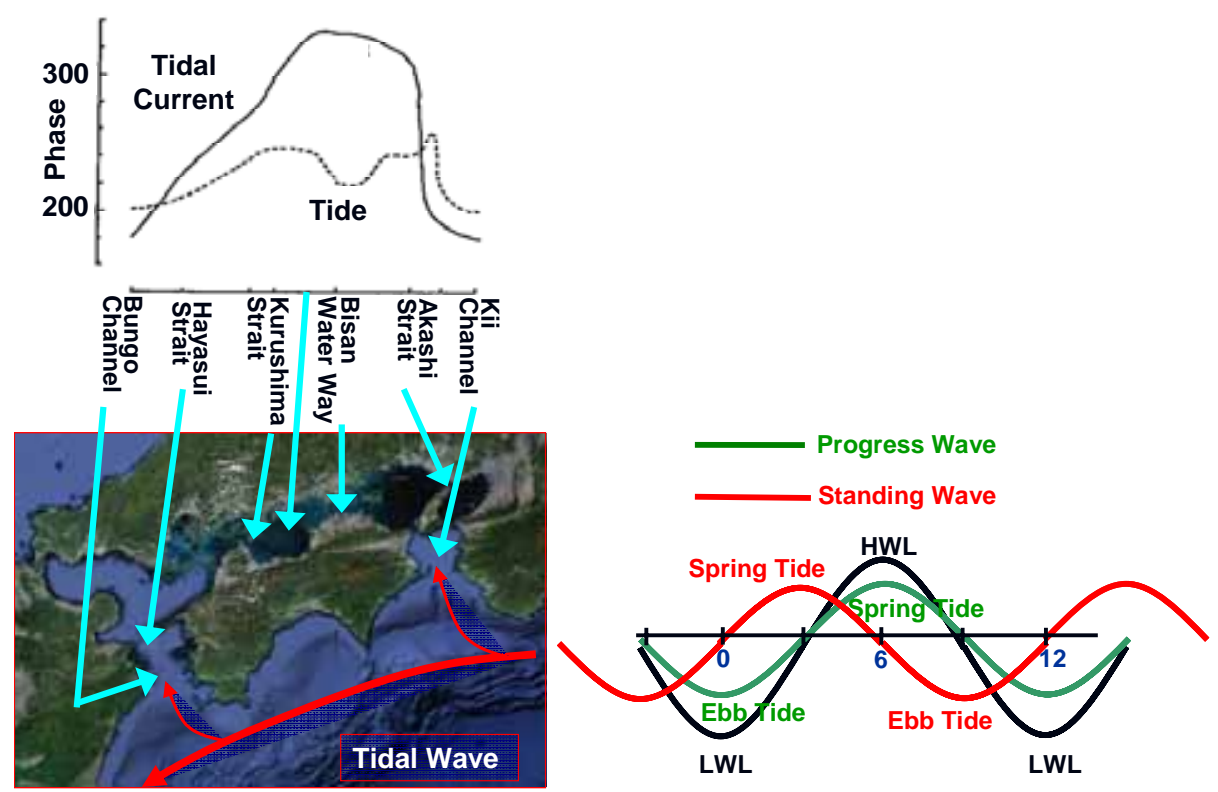

Figure 17. Characteristics of Tide and Tidal Current oscillation in the Seto Inland Sea.

\section{Analysis of Tsunami propagation}

Fig. 18 shows the diagram of initial condition and maximum tsunami height in the eastern part of The Seto Inland Sea. Tsunami incident wave propagates into Seto Inland Sea through the Kii Channel. The reflected waves generate on the progress process of tsunami in the Seto Inland Sea. Tsunami wave height decreases due to propagation through the straits. Tsunami wave propagate into the basins and the reflected waves generate in the basins.

Fig. 19 shows the distribution of tsunami height by predominant frequency component in the Kii Channel, eastern mouth of the Seto Inland Sea. This diagram shows the frequency spectrum at 2 points, which are north and south side of the Kitan Strait and Naruto Strait. The characteristic of frequency changes on the process of tsunami propagation through the straits. Typical characteristic is that high frequency components decrease wave energy. 

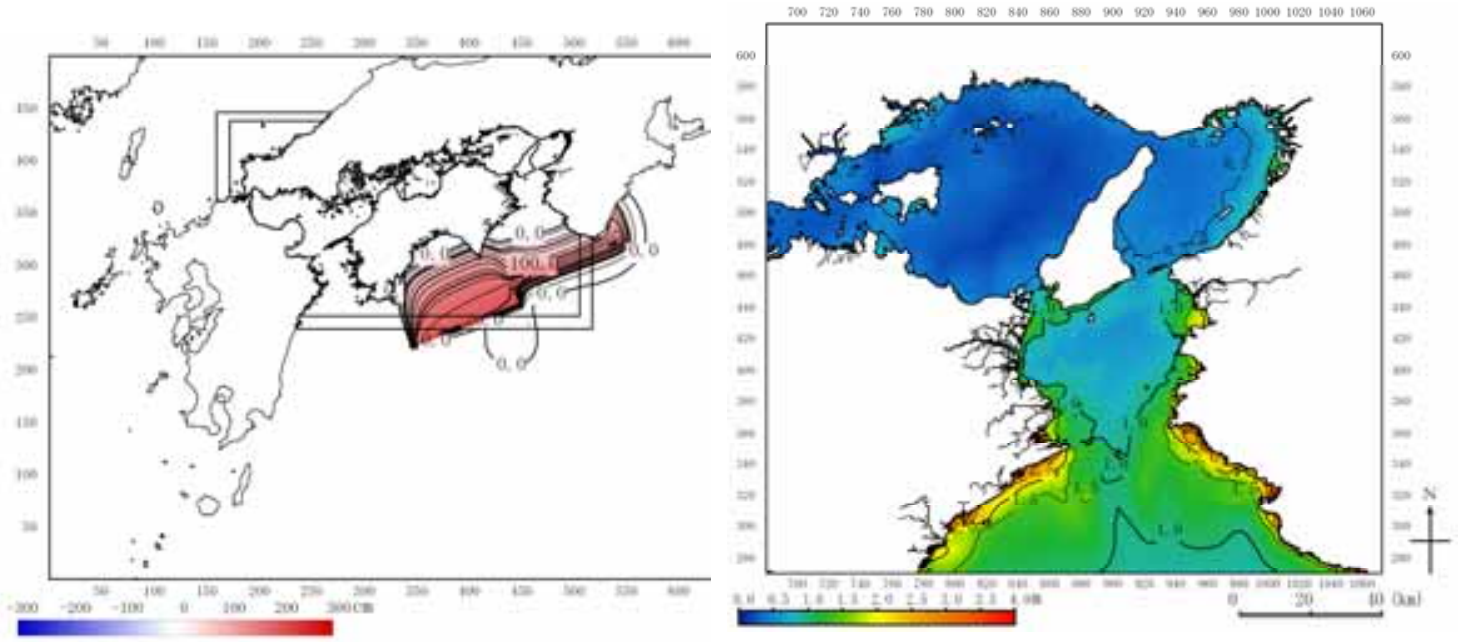

Figure 18 Distribution of Initial condition and maximum tsunami height in the eastern part of The Seto Inland Sea.

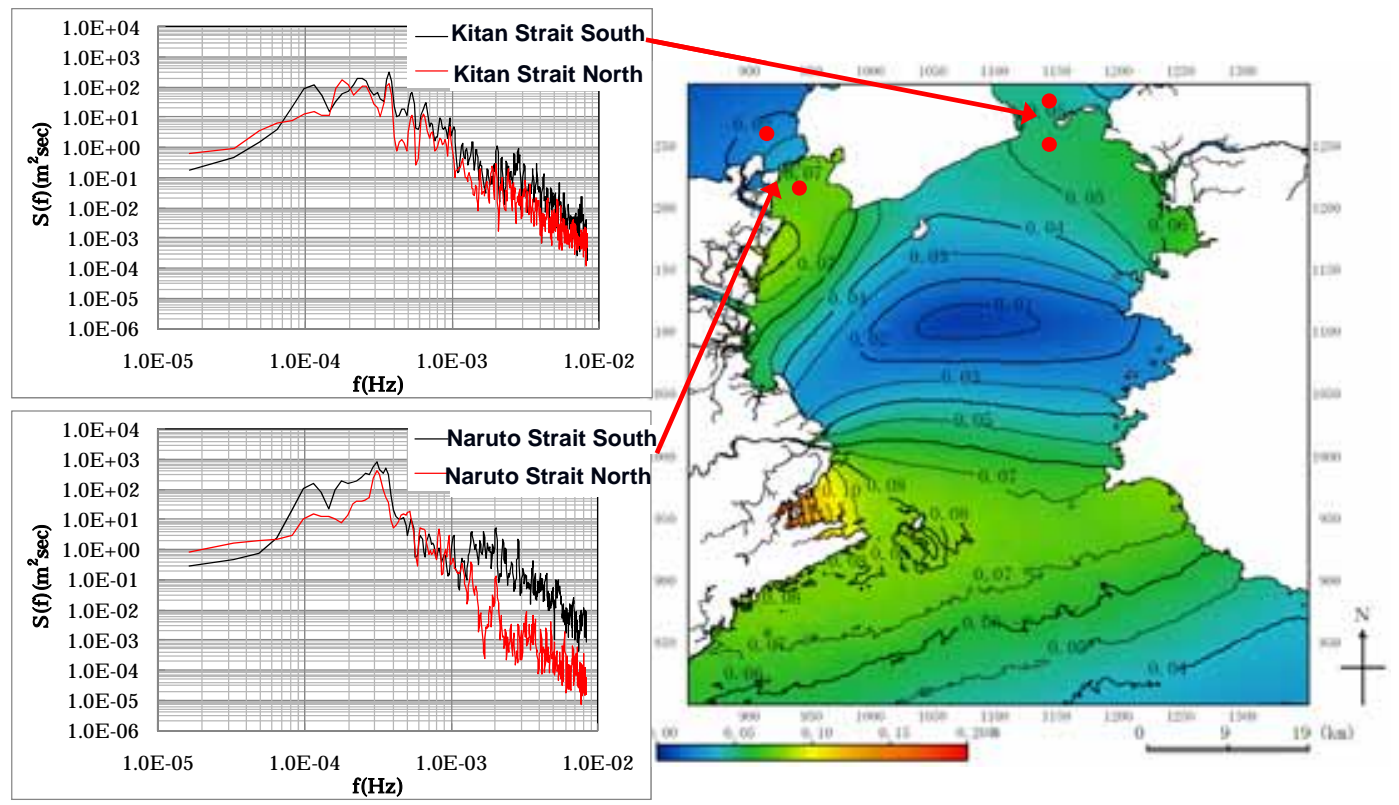

Figure 19 Distribution of tsunami height by predominant frequency component in the Kii Channel, eastern mouth of the Seto Inland Sea and frequency spectrum around the straits.

\section{Analysis of Storm Surge Generation}

Fig. 20 shows the distribution of maximum tide anomaly due to storm surge generated by Typhoon 0418 around the western part of Japan. Red line shows the route of typhoon 0418 in this diagram. Fig. 21 is the distribution of maximum tide anomaly in the Seto Inland Sea due to storm surge generated by Typhoon 0418. Upper diagrams show the comparisons between simulation and observation about time series of storm surge at western and eastern tide gauge point in the Seto Inland Sea. Characteristics of Storm Surge generated by Typhoon 0418 in the Seto Inlad Sea are as following. Storm Surge is generated by strong westward wind, and tide anomaly is larger at the eastern part of particular basins. Tide anomaly of Storm Surge simulation underestimates about $0.3 \mathrm{~m}$ from the comparison with observed one.

The trial storm surge simulations are performed for explanation about the analysis of generation mechanism. One of trial condition is that atmospheric pressure is taken into account for the generation forth of storm surge. Wind stress is not taken into account for the simulation condition. According to 
this case, the effect of atmospheric pressure is clarified. Another condition is that the basins are divided by imaginary boundaries. According to this case, the influence of water transport from adjacent sea area is clarified.

Fig. 22 shows the result of trial storm surge simulations. Red circle shows a target basin which is the central part of Seto Inland Sea. Fig.23 shows the time series of tide anomaly, based on the trial storm surge simulations, at the coast points in the central bay in the Seto Inland Sea. Black lines are the standard case. Red lines are the case of taking into account atmospheric pressure. Blue lines are the case of basins divided by imaginary boundary. Generation mechanism of storm surge in Seto Inland Sea is summarized. Large water volume is transported from adjacent sea area, for example outer basins and open sea. The effect of atmospheric pressure due to typhoon 0418 is about $0.5 \mathrm{~m}$ in the total storm surge level. Water mass is transported from western part to eastern part by strong westward wind in particular basins.

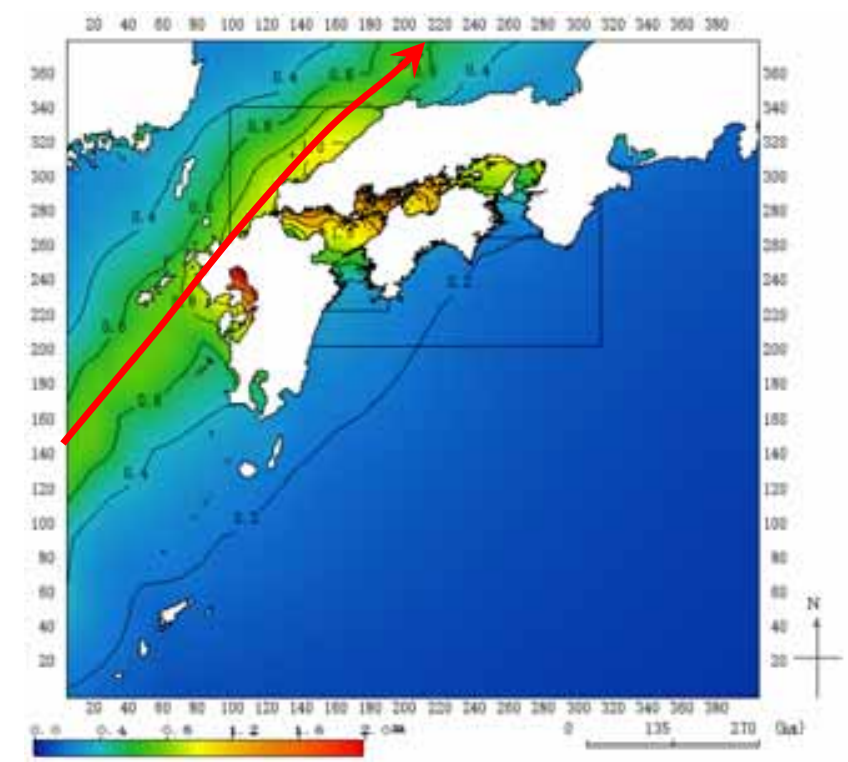

Figure 20 Distribution of maximum tide anomaly due to storm surge generated by Typhoon 0418 around the western part of Japan and the route of typhoon (Red line).

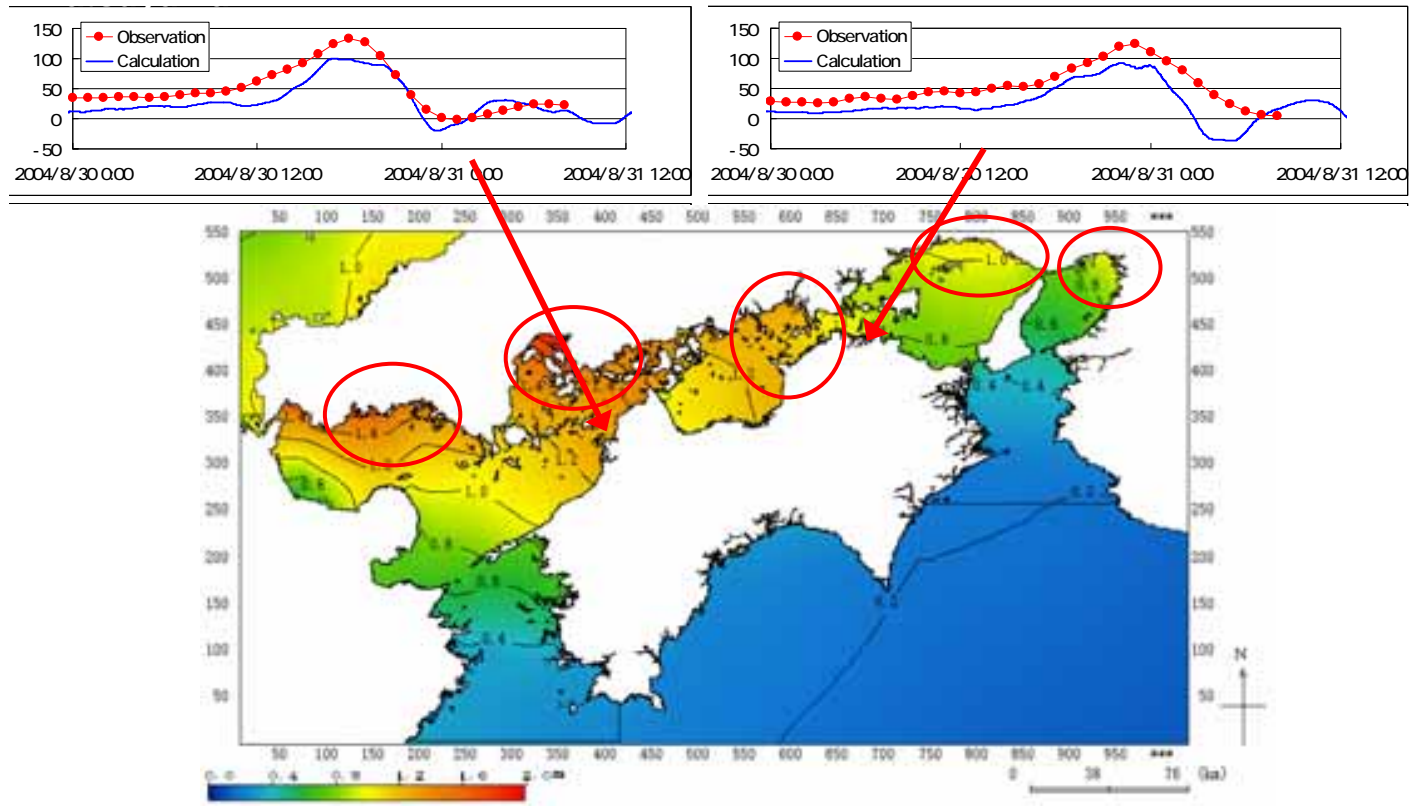

Figure 21 Ddistribution of maximum tide anomaly in the Seto Inland Sea due to storm surge generated by Typhoon 0418 and comparisons between simulation and observation about time series of storm surge. 

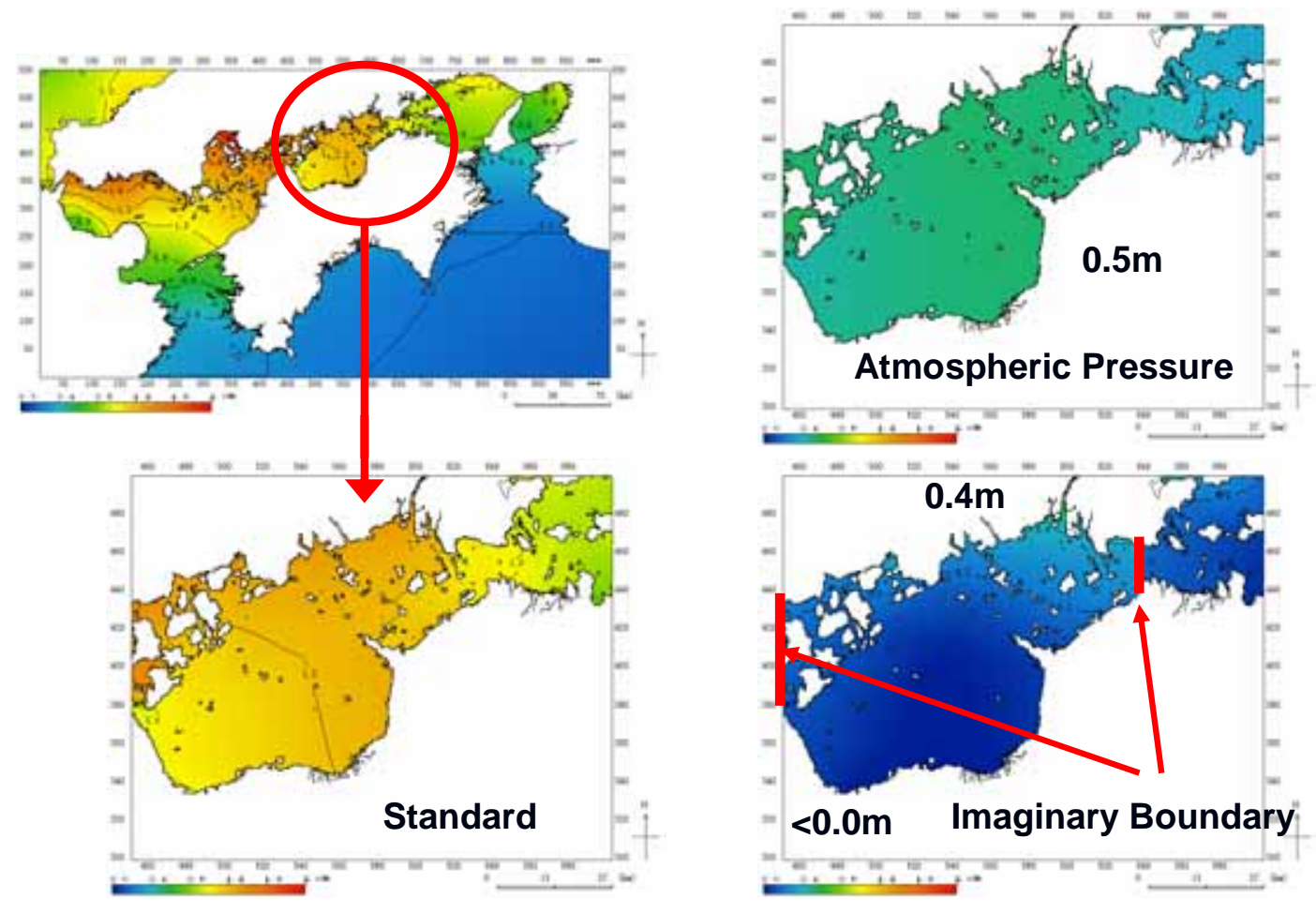

Figure 22 Distribution of maximum tide anomaly due to trial storm surge simulations, trial cases are standard, atmospheric pressure forth, imaginary boundary.

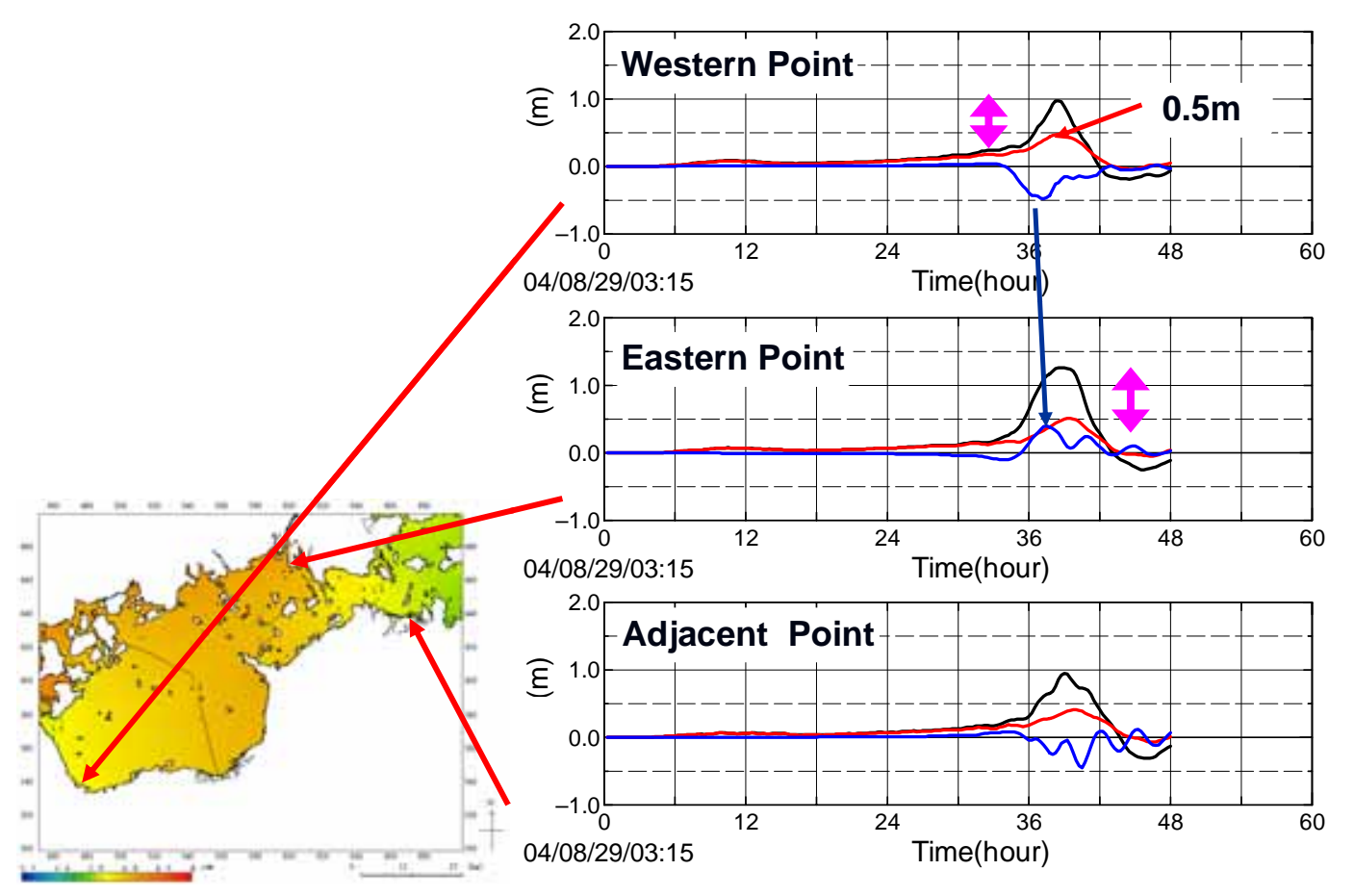

Figure 23 Comparison of time series about tide anomaly due to trial storm surge simulations at the western, eastern and adjacent points on the coasts of the central bay in the Seto Inland Sea. 


\section{CONCLUSIONS}

The INSPECT (Integrated Numerical research System for Prevention and Estimation of Coastal disasTer) system has been developed for coastal protection works composed of hard and soft countermeasures. The INSPECT system is employed for the study and prevention various disasters on Japanese coasts due to waves, storm surges, and tsunamis. Application of INSPECT system is performed in the Shikoku Island, Japan. Several characteristics are clarified with the analysis used by INSPECT system. The system continues to be upgraded and to be extended for numerical studies of all coastal and estuarine areas.

\section{ACKNOWLEDGMENTS}

The authors would like to express their thanks to Emeritus Prof. Yoshimi Goda at Yokohama National University and Emeritus Prof. Akira Watanabe at University of Tokyo for their precious advices. The authors also would like to record their sincere thanks to the late Dr. Chiaki Goto for his valuable ideas and advices.

\section{REFERENCES}

Aida, I. 1984. A source model of the tsunami accompanying the 1983 Nihonkai-Chubu Earthquake, Bull. Eartheq. Res. Inst., Vol.59, 235-265.

Iwase, H. and F. Imamura. 2003. A new tsunami numerical simulation with Boussinesq-type equations applied for the 1983 Nihonkai-Chubu Earthquake Tsunami, Proc. of the $2^{\text {nd }}$ Int. Conf. Asian and Pacific Coasts 2003, 12-13.

Longuet-Higgins, M.S. and R.W. Stewart. 1964. Radiation stresses in water waves: A physical discussion with applications, Deep-Sea Res., Vol.11, 529-562.

Shibaki, H. and A. Watanabe. 2002. Study of multi-level simulation model for storm surge considering density stratification and wave setup, J. Hydraulics, Coastal and Envir. Eng., JSCE, No.719/ II -61, 47-66 (in Japanese). 